\title{
Neural Recovery Function of the Auditory Nerve in Cochlear Implant Surgery: Comparison between Prelingual and Postlingual Patients
}

\author{
Bettina Carvalho $^{10}$ Gislaine Richter Minhoto Wiemes ${ }^{10}$ Luiz Patrial Netto ${ }^{10}$ \\ Rogerio Hamerschmidt ${ }^{1}$ (1) \\ ${ }^{1}$ Hospital Paranaense de Otorrinolaringologia, Curitiba, Paraná, Brazil \\ Address for correspondence Bettina Carvalho, Master, Hospital \\ Int Arch Otorhinolaryngol 2020;24(4):e444-e449. \\ Paranaense de Otorrinolaringologia, Avenida República Argentina, \\ 2069, Água Verde, Curitiba, PR, 80620-010, Brazil \\ (e-mail: bettinacarvalho@yahoo.com.br).
}

\author{
Abstract \\ Keywords \\ - cochlear implants \\ - prelingual hearing \\ loss \\ - postlingual hearing \\ loss \\ - neural response \\ telemetry
}

Introduction Cochlear implants (Cls) enable objective measures of the neural function in implanted patients through the measurements of the neural response telemetry (NRT) and of the Auditory nerve Recovery Function (REC). These measurements help in programming the speech processor and understanding the auditory system.

Objective To compare the NRT and the REC in prelingual and postlingual implanted patients.

Methods An observational, descriptive and prospective study was carried out. The NRT and the REC (through the T0, A, and tau parameters) were evaluated in individuals submitted to $\mathrm{Cl}$ surgery, who were divided into two groups: prelingual and postlingual patients.

Results In total, 46 patients were evaluated. Data analysis showed no statistically significant difference between the NRT measurements and the T0, A, and Tau of the REC in the comparison between the two groups, except for the NRT in the basal cochlear region.

Conclusion There was no statistically significant difference in the REC in pre- and postlingual patients.

\section{Introduction}

The age at the onset of deafness is one of the most important factors in the evaluation of a patient with hearing loss (HL). Regarding this aspect, HL can be classified according to the period of language acquisition as prelingual or postlingual. It is said to be prelingual when it occurs before the acquisition of the bases of oral language, and it is postlingual when it occurs after the acquisition of language, when the patient already has an established linguistic code. ${ }^{1}$

Auditory deprivation in prelingual HL may affect the development of the auditory neural pathways, since the maturation of these pathways depends on stimulation. This deprivation compromises the maturation of the central auditory pathways, as well as the development of speech and language skills ${ }^{2}$. In postlingual $\mathrm{HL}$, the neural pathways are already formed, and there is an auditory memory, so, in general, there is no regression of the language due to hearing deprivation.

The development of speech perception and language acquisition, as well as the success of the $\mathrm{CI}$ rehabilitation, both in children with prelingual HL and in adults with pre- or postlingual $\mathrm{HL}$, depends on some determinant factors, ${ }^{3}$ but since the ganglion cells of the auditory nerve are considered the elements that effectively respond to the electrical stimulus released by the $\mathrm{CI}$, the participation of the ganglion cells is the differential factor in the individual's ability to achieve success with the use of the $\mathrm{CI}^{4}$ received

April 29, 2019

accepted

December 26, 2019
DOI https://doi.org/

$10.1055 / \mathrm{s}-0040-1702974$. ISSN 1809-9777.
Copyright (e) 2020 by Thieme Revinter

Publicações Ltda, Rio de Janeiro, Brazil
License terms

(c) $(1) \$$ 
Both the neural function of the cochlear nerve as well as the number, distribution, and functionality of the remaining neural cells must be in sufficient quantity to enable the electrical stimulation to be transmitted to the cerebral cortex $^{5}$. This functionality can be evaluated through speech performance or electrophysiological tests.

Initial studies ${ }^{6-8}$ compared the performance with the $\mathrm{CI}$ between postlingual and prelingual adult patients. They observed worse responses in the performance of prelingual patients. Other studies ${ }^{9,10}$ have shown that only prelingual children who are implanted early (before 6 years of age) have achieved full speech recognition in an open set, with an even better performance than the postlingual patients. In the first 6 years of age, a period of high neuronal plasticity $^{9,10}$ was reached with $\mathrm{CI}$ stimulation, close to that of a normal listener.

Ching et al $^{11}$ showed the benefit of early intervention for language development, helping to ensure early amplification and enable cochlear implantation after the diagnosis.

The possibility of performing $\mathrm{Cl}$ in small children makes it necessary to use objective measurements to aid in the programming of the speech processor. One of them is neural response telemetry (NRT), through which the electrically-evoked compound action potential (ECAP) is obtained using the implant itself to elicit the stimulus and record the responses to study the remaining neural properties $^{12}$ without the need to sedate the patient. ${ }^{13}$ The refractory recovery function (REC) can be extracted from the action potential of the neural fibers in response to the use of a pulse with a gap between the main stimulus and the masker. ${ }^{14}$

The REC is measured by an exponential function with three parameters: 'TO', 'A' and 'tau'. T0 is the absolute refractory period (in $\mu \mathrm{s}$ ); $\mathrm{A}$ is the maximum amplitude of the neural response at the maximum saturation level (in $\mu \mathrm{V})$; and tau is the recovery time constant during the relative refractory period (in $\mu \mathrm{s}$ ). It is important to consider the interaction between the three parameters. ${ }^{14-16}$

The objective of the present study was to evaluate and compare the NRT and the REC of pre- and postlingual implanted patients.

\section{Methods}

An observational, prospective and descriptive study was carried out, with the approval of the institutional Ethics Committee on Research in Human Beings under the CAAE: 69604917.2.0000.5529, registered under CEP 185/2017.

Our institution is an ear, nose and throat (ENT) specific hospital, and the study took place from January to November 2017.

Table 1 Inclusion and exclusion criteria
The study included participants undergoing CI surgery, who were divided into two groups:

1. Prelingual: congenital HL or HL that occurred before the acquisition of language;

2. Postlingual: HL that occurred after the acquisition of language.

We included patients who were submitted to the $\mathrm{CI}$ and to the intraoperative assessments that are part of our routine (-Table 1). The indications for the $\mathrm{CI}$ are well known in the literature.

There was no randomization of the patients, because the groups were based on preexisting conditions (age of acquisition of language). No patients were lost to follow-up.

The CI used was the Freedom Implant Contour Advance CI24RE (CA) (Cochlear Ltd, Sidney, Australia), and, to record the impedances, the ECAP and the REC, we used the Custom Sound EP 4.4 software (Cochlear Ltd.), which controls the parameters of stimulation and recording, and is installed in a computer coupled to the portable programming interface (portable programming system) and the speech processor CP810 Sound Processor (Cochlear Ltd.).

During the surgery, shortly after the insertion of the electrodes into the cochlea, impedance telemetry (IT) was performed to evaluate the integrity and functionality of the electrodes. Then, the measurement of the Threshold NRT (TNRT), Automatic NRT (autoNRT) was performed using 5 or 9 electrodes corresponding to the frequency bands, according to cochlear tonotopy. The current level (CL) at each electrode started at 170 current units ( $\mathrm{cu}$ ), with a range of $6 \mathrm{cu}$ between one stimulus and the other, until the maximum stimulation of $255 \mathrm{cu}$, or until the T-NRT was found. The parameters were the software's default settings.

The REC was the next measurement. We used advanced NRT to create a new series 'Recovery,' and chose 3 electrodes obeying cochlear tonotopy. The electrodes were divided according to their position within the cochlea in the apical (22-16), medial (15-8) and basal (7-1) regions.

The masking level was set at $10 \mathrm{cu}$ above the $\mathrm{CL}$ used for pacing (probe level). The interpulse interval was set at $500 \mu \mathrm{s}$, and the pacing rate was $80 \mathrm{~Hz}$ in a series of $25 \mu$ s per phase. The REC uses 20 interval values between the triggering of the stimulus on the masking electrode and the triggering of the stimulus on the electrode tested (between $100 \mu \mathrm{s}$ and $10,000 \mu \mathrm{s})$. Other parameters, such as amplification gain, time interval between stimulus end and response recording (defined as the number of artifacts to enable a better visualization of the $\mathrm{N} 1$ wave), and the distance between MP1 and MP2, were adjusted and modified according to the proposition made by Abbas et $\mathrm{al}^{13}$ and Lai. ${ }^{17}$ The level of the stimulus used for the REC recordings was an average of $20 \mathrm{cu}$

\begin{tabular}{|l|l|}
\hline Inclusion criteria & Exclusion criteria \\
\hline $\begin{array}{l}\text { Patients (male and female children and adults) submitted to cochlear implants and } \\
\text { intraoperative assessments. }\end{array}$ & Neurological or cognitive deficit. \\
\hline
\end{tabular}


above the level at which the NRT was obtained in each stimulated electrode (apical, medial and basal), with attention to obtain a neural response, and not to cause saturation of the amplifier.

The software automatically transforms REC measurements into an exponential function, a mathematical model proposed by Müller-Deile et $\mathrm{al}^{18}{ }^{18}$ which defines that: $\mathrm{F}$ Masker Probe Interval (MPI) $=$ A (1-exp [- $\alpha$ (MPI-T0)]).

We performed a descriptive analysis of the data through frequencies, measurements of central tendency (mean and median) and dispersion (standard deviation, minimum and maximum) of variables. Neural recovery parameters T0', A and tau, as well as the CL for the REC, were recorded for the apical, medial and basal electrodes in both groups. The results of the quantitative variables were described by means and standard deviations, medians and amplitudes. For the categorical variables, frequencies and percentages were presented. The comparison between the groups in relation to the NRT and the REC measurements (T0, A and tau) was performed using the Student $t$-test for independent samples. The normality of the variables was evaluated by the Kolmogorov-Smirnov test. Values of $p<0.05$ indicated statistical significance. The data were analyzed using the Stata/SE (StataCorp LLC, College Station, TX, US) software, version 14.1.

\section{Results}

In the prelingual group, 22 patients were included, 4 of which were bilateral, resulting in 26 ears, aged between 10 and 46 years. In the postlingual group, there were 24 patients, 4 of whom were bilateral, resulting 28 ears, aged between 22 and 62 years. In total, 54 ears were evaluated.

The age of the sample ranged from 10 to 62 years. The mean age of the prelingual patients was 28.3 years, and the mean duration of the HL was 27.7 years. For the postlingual patients, the mean age was 44.1 years, and the mean duration of the HL was 11.1 years.

The causes of HL for all patients are included in - Table 2.

For all patients, the CI presented IT of the electrodes within normal values during surgery, showing that the electrodes were capable of being activated. The results of the intraoperative NRT for the apical, medial and basal electrodes are shown in table 3. There was no difference between groups for the apical and medial NRT, but there was a difference for the basal NRT.
Table 2 Patients according to the etiology of the hearing loss

\begin{tabular}{|l|l|l|}
\hline \multirow{2}{*}{ Etiology } & \multicolumn{2}{|l|}{ Group } \\
\cline { 2 - 3 } & Postlingual & Prelingual \\
\hline Idiopathic & $14(50 \%)$ & $1(3.8 \%)$ \\
\hline Genetic & $8(28.6 \%)$ & $7(26.9 \%)$ \\
\hline Ménière syndrome & $1(3.6 \%)$ & \\
\hline Parry-Romberg syndrome & $2(7.1 \%)$ & \\
\hline Traumatic brain injury & $1(3.6 \%)$ & \\
\hline Otosclerosis & $2(7.1 \%)$ & \\
\hline Prematurity & & $2(7.7 \%)$ \\
\hline Neonatal jaundice & & $1(3.8 \%)$ \\
\hline Rubella & & $9(34.6 \%)$ \\
\hline Meningitis & & $1(3.8 \%)$ \\
\hline Uscher syndrome & & $1(3.8 \%)$ \\
\hline Congenital & & $1(3.8 \%)$ \\
\hline Measles & & $1(3.8 \%)$ \\
\hline Cytomegalovirus & & $2(7.7 \%)$ \\
\hline Total & 28 & 26 \\
\hline
\end{tabular}

The REC results are shown in table 4. No differences were found in any of the three parameters for each electrode.

\section{Discussion}

It is suggested that auditory maturation of the brainstem, measured through neural potentials, occurs between 1 and 3 years of age in hearing people. For implanted patients, however, it is not so clear, given that the characteristics of the auditory system in adults using the $\mathrm{CI}$ may be different from those of children using the $\mathrm{Cl}$. Many adults have postlingual deafness, acquired after the normal development of the auditory system in childhood, promoted by binaural hearing, while many children receiving implants have bilateral congenital deafness. In prelingual children, the lack of auditory input during the primary stages of development may alter the normal maturation of the central auditory system. On the other hand, adults may experience long periods of deafness, during which varying degrees of neural degeneration may occur in the auditory pathways. ${ }^{19}$

Table 3 Neural response telemetry (NRT) results

\begin{tabular}{|l|l|l|l|l|l|l|l|l|}
\hline Variables & Group & $\mathbf{n}$ & Mean & Median & Minimum & Maximum & Standard deviation & $p_{\text {-value }}$ \\
\hline NRT - apical & Postlingual & 28 & 179.9 & 183 & 84 & 228 & 27.2 & \\
\hline & Prelingual & 26 & 183.6 & 185 & 144 & 222 & 21.5 & 0.585 \\
\hline NRT - medial & Postlingual & 28 & 195.9 & 197 & 156 & 240 & 17.3 & 13.0 \\
\hline & Prelingual & 26 & 194.6 & 196.5 & 170 & 220 & 22.5 & 0.755 \\
\hline NRT - basal & Postlingual & 28 & 191.2 & 190.5 & 145 & 225 & 24.8 & \\
\hline & Prelingual & 26 & 172.3 & 169 & 136 & 226 & 24 & 0.005 \\
\hline
\end{tabular}

Note: ${ }^{*}$ Student $t$-test for independent samples; $p<0.05$. 
Table 4 Neural recovery function (REC) results

\begin{tabular}{|l|l|l|l|l|l|l|l|l|l|}
\hline Variables & Region & Group & N & Mean & Median & Minimum & Maximum & Standard deviation & $p$-value * \\
\hline T0 & Apical & Postlingual & 28 & 534.8 & 496 & 186 & 1108 & 240.4 & \\
\hline & & Prelingual & 26 & 467.8 & 452 & 131 & 1071 & 218.1 & 0.290 \\
\hline & Medial & Postlingual & 28 & 611.8 & 604 & 233 & 1189 & 255.7 & \\
\hline & & Prelingual & 26 & 694.9 & 638.5 & 32 & 1599 & 343.2 & 0.315 \\
\hline & Basal & Postlingual & 28 & 482.1 & 456.5 & 128 & 855 & 184.0 & \\
\hline & & Prelingual & 26 & 457.7 & 514 & 31 & 810 & 201.2 & 0.643 \\
\hline & Apical & Postlingual & 28 & 113.6 & 96 & 19 & 376 & 75.2 & \\
\hline & & Prelingual & 26 & 114.0 & 105.5 & 11 & 250 & 65.8 & 0.984 \\
\hline & Medial & Postlingual & 28 & 124.5 & 112 & 24 & 403 & 81.3 & \\
\hline & & Prelingual & 26 & 139.2 & 96.5 & 20 & 509 & 119.1 & 0.596 \\
\hline & Basal & Postlingual & 28 & 80.8 & 69.5 & 20 & 238 & 52.9 & \\
\hline Tau & & Prelingual & 26 & 66.9 & 60 & 16 & 183 & 40.9 & 0.289 \\
\hline & Apical & Postlingual & 28 & 834.1 & 792.5 & 11 & 1870 & 558.7 & \\
\hline & & Prelingual & 26 & 680.2 & 706 & 35 & 1499 & 460.1 & 0.276 \\
\hline & Medial & Postlingual & 28 & 1046.5 & 1062.5 & 11 & 1967 & 423.9 & \\
\hline & & Prelingual & 26 & 1222.7 & 1427 & 24 & 1865 & 546.5 & 0.190 \\
\hline & Basal & Postlingual & 28 & 923.1 & 994.5 & 12 & 1827 & 443.9 & \\
\hline & & Prelingual & 26 & 1115.6 & 1122 & 16 & 1967 & 538.8 & 0.157 \\
\hline
\end{tabular}

Note: ${ }^{*}$ Student $t$-test for independent samples; $p<0.05$.

Previous studies that compared pre- and postlingual implanted patients observed their performance through speech tests. Hinderink et $\mathrm{al}^{20}$ compared 19 pre- and postlingual adult patients who received $\mathrm{CI}$ through discrimination tests and concluded that the group of postlingual patients had a performance in the closed-set and tests of auditory perception superior to that of the prelingual ones. Results similar to those are found in the literature ${ }^{7,21}$.

Kraaijenga et $\mathrm{al}^{22}$ retrospectively studied the factors that influenced outcomes in 428 adult implanted patients. They used consonant-vowel-consonant scores before and after implantation as a measure, dividing the sample into preand postlingual patients. They observed that in postlingual patients the preimplantation speech perception score and age at onset of the HL were positive predictive factors, and meningitis and otosclerosis as etiology are negative factors for postimplant speech perception. In prelingual patients, the only strong positive predictive factor was the perception of preimplant speech. The age at implant was not a significant factor in either group.

On the other hand, correlations between speech perception and nerve cell count are probably complicated by several factors: it is unlikely that speech perception scores and spiral ganglion counts have a direct and linear correlation; the processed speech provided by the $\mathrm{Cl}$ may contain redundant information that could effectively mask the functional changes that may occur at the peripheral level; in many implant users, there are large variations in ECAP measurements, such as limiting and tilting the growth function through electrodes within an individual implant user, because speech perception is usually measured using the entire set of electrodes, and these variations can affect correlations with performance; and speech perception may be influenced by changes in central nervous system plasticity or by additional patient (cognitive) variables not related to the auditory periphery ${ }^{23}$.

Some authors evaluated brain function comparing preand postlingual implanted patients. Naito et $\mathrm{a}^{24}$ evaluated changes in regional cerebral blood flow in the auditory cortex induced by sound stimulation. They concluded that the neural networks for speech processing in the area of auditory association in postlingual deaf subjects are similar to those of normal hearing subjects, whereas in prelingual deaf patients who received the $\mathrm{Cl}$ after the acquisition of language, this area may not develop completely. Okazawa et $\mathrm{al}^{25}$ evaluated brain scanning through positron-emission tomography (PET) and magnetic resonance imaging (MRI) scans. Their findings suggest that the cortical representation of language is not dependent on prior auditory experience, whereas processing in the primary auditory cortex is dependent on experience.

With respect to the NRT and the REC, few studies performed evaluations based on the differences between pre and postlingual patients. Carvalho et $\mathrm{al}^{26}$ compared the values of the NRT in children (aged between 9 months and 11 years) and adults (age range: 18 to 83 years), and showed no difference in the comparison of these two groups except for the saturation level ' $A$ ' in the basal cochlear region. The patients who were children were mostly prelingual, and the adults were mostly postlingual. 
In the present study, we showed that in the same NRT comparison between postlingual and prelingual patients, there was a statistically significant difference in the same basal cochlear region. This may have been due to the fact that the studied groups were similar: children and adults, and prelingual and postlingual groups, even though our mean age was higher for the prelingual group (28.3 years). In addition, we believe that these differences may have occurred because the apical $\mathrm{T} 0$ values for the prelingual group were lower than the apical T0 values for the postlingual group. The same was true for baseline A values for the postlingual group, which were lower than those of the prelingual group.

In a retrospective study, Kutscher et $\mathrm{al}^{27}$ evaluated children and adults regarding REC measurements and their correlation with etiology, the duration of the HL, and the duration of the use of hearing aids before the CI. There was no statistically significant correlation between the analyzed factors and the REC. However, the authors found that there may be a trend: the shorter the duration of the HL, the faster the REC.

Even though software to collect data from the $\mathrm{CI}$ manufacturers are highly sophisticated, they are not perfect. The influence of artifacts and the quality of recorded potentials may vary between patients and with the selection of stimulation parameters. Even with certain pathologies, such as ossification of the cochlear lumen in otosclerosis, ECAPs may be difficult to collect. ${ }^{23}$

The fact that there was no statistical correlation between the preoperative data and the REC measurements leads us to question whether recording the NRT and the REC with the methodology proposed by Abbas et $\mathrm{al}^{13}$ is sensitive and specific, even considering that the authors evaluated only postlingual patients, and that the purpose of their investigation was to enable the recording of the ECAP in the majority of patients with $\mathrm{Cl}$.

Other studies, such as the one by Miller et al, ${ }^{28}$ report new research on ECAP measurements, as well as possible methods, interpretations, and implications on neural functions.

Alvarez et $\mathrm{al}^{29}$ analyzed the use of ECAP recordings to aid in the activation of the electrodes in the map of implanted patients, comparing pre- and postlingual patients. They found no statistically significant differences between the two groups regarding ECAP thresholds. But there was a difference in the $\mathrm{C}$ levels measured by the audiologist. These were greater in prelingual than in postlingual patients. So the authors came up with different equations to estimate $C$ levels based on ECAP responses.

We believe that future studies can clarify these doubts and bring new uses for the objective measurements of neural function.

\section{Conclusion}

No statistically significant difference in the values of the measurements of the REC, comparing prelingual and postlingual patients, was found. There were only differences in the basal region of the cochlea in the evaluation of the NRT between the groups, and in the evaluation of the T0, A and tau measurements individually for each group.
We suggest that new studies should compare REC measurements to speech perception performance tests or patient preferences in the choice of parameters to be used in programming the $\mathrm{Cl}$.

\section{Conflict of Interests}

The authors have none conflict of interests to declare.

\section{References}

1 Oliveira P, Castro F, Ribeiro A. Surdez infantil. Rev Bras Otorrinolaringol 2002;68:417-423

2 Sharma A, Tobey E, Dorman M, et al. Central auditory maturation and babbling development in infants with cochlear implants. Arch Otolaryngol Head Neck Surg 2004;130(05):511-516

3 Guedes MC, Weber R, Goffi-Gomez MVS, Brito Neto RV, Peralta CGO, Bento RF. Efeitos do potencial de ação neural sobre a percepção de fala em usuários de implante coclear. Rev Bras Otorrinolaringol 2007;73:660-667

4 Simmons FB, Lusted HS, Meyers T, Shelton C. Electrically induced auditory brainstem response as a clinical tool in estimating nerve survival. Ann Otol Rhinol Laryngol Suppl 1984;112:97-100

5 Cohen LT. Practical model description of peripheral neural excitation in cochlear implant recipients: 5 . refractory recovery and facilitation. Hear Res 2009;248(1-2):1-14

6 Eddington DK, Dobelle WH, Brackmann DE, Mladejovsky MG, Parkin JL. Auditory prostheses research with multiple channel intracochlear stimulation in man. Ann Otol Rhinol Laryngol 1978; 87(6 Pt 2):1-39

7 Busby PA, Roberts SA, Tong YC, Clark GM. Results of speech perception and speech production training for three prelingually deaf patients using a multiple-electrode cochlear implant. $\mathrm{Br} \mathrm{J}$ Audiol 1991;25(05):291-302

8 Busby PA, Tong YC, Clark GM. Electrode position, repetition rate, and speech perception by early- and late-deafened cochlear implant patients. J Acoust Soc Am 1993;93(02):1058-1067

9 Manrique M, Cervera-Paz FJ, Huarte A, Perez N, Molina M, GarcíaTapia R. Cerebral auditory plasticity and cochlear implants. Int J Pediatr Otorhinolaryngol 1999;49(Suppl 1):S193-S197

10 Harrison RV, Gordon KA, Mount RJ. Is there a critical period for cochlear implantation in congenitally deaf children? Analyses of hearing and speech perception performance after implantation. Dev Psychobiol 2005;46(03):252-261

11 Ching TYC, Dillon H, Button L, et al. Age at Intervention for Permanent Hearing Loss and 5-Year Language Outcomes. Pediatrics 2017;140(03):e20164274

12 Guedes MC, Brito Neto RV, Goffi-Gomez MVS, et al. Telemetria de resposta neural intra-operatoria em usuários de implante coclear Nucleus 24. Rev Bras Otorrinolaringol 2005;71:660-667

13 Abbas PJ, Brown CJ, Shallop JK, et al. Summary of results using the nucleus CI24M implant to record the electrically evoked compound action potential. Ear Hear 1999;20(01):45-59

14 Botros A, Psarros C. Neural response telemetry reconsidered: II. The influence of neural population on the ECAP recovery function and refractoriness. Ear Hear 2010;31(03):380-391

15 Battmer RD, Dillier N, Lai WK, et al. Evaluation of the neural response telemetry (NRT) capabilities of the nucleus research platform 8: initial results from the NRT trial. Int J Audiol 2004;43 (Suppl 1):S10-S15

16 Morsnowski A, Charasse B, Collet L, Killian M, Müller-Deile J. Measuring the refractoriness of the electrically stimulated auditory nerve. Audiol Neurotol 2006;11(06):389-402

17 Lai WK. An NRT cookbook. Basel, Switzerland: Cochlear AG; 1999

18 Müller-Deile J, Mornowski A, Charasse B, Thai-Van H, Killian M. Correlation of auditory nerve refractoriness and the offset between auditory nerve response thresholds and psychophysical 
thresholds in Nucleus cochlear implant recipients. In: Sheperd RK, Svirsky MA (Eds.) Abstracts of the 2003 Conference on Implantable Auditory Prostheses. Toulouse2003:178

19 Gordon KA, Papsin BC, Harrison RV. An evoked potential study of the developmental time course of the auditory nerve and brainstem in children using cochlear implants. Audiol Neurotol 2006; 11(01):7-23

20 Hinderink JB. Men's LHM, Brokx JPL, Can Den Broek P. Performance of prelingually and postlingually deaf patients using single-channel or multichannel cochlear implants. Laryngoscope 1995;105:618-622

21 Tong YC, Busby PA, Clark GM. Perceptual studies on cochlear implant patients with early onset of profound hearing impairment prior to normal development of auditory, speech, and language skills. J Acoust Soc Am 1988;84(03):951-962

22 Kraaijenga VJC, Smit AL, Stegeman I, Smilde JJM, van Zanten GA, Grolman W. Factors that influence outcomes in cochlear implantation in adults, based on patient-related characteristics - a retrospective study. Clin Otolaryngol 2016;41(05):585-592

23 Miller CA, Brown CJ, Abbas PJ, Chi SL. The clinical application of potentials evoked from the peripheral auditory system. Hear Res 2008;242(1-2):184-197
24 Naito Y, Hirano S, Honjo I, et al. Sound-induced activation of auditory cortices in cochlear implant users with post- and prelingual deafness demonstrated by positron emission tomography. Acta Otolaryngol 1997;117(04):490-496

25 Okazawa H, Naito Y, Yonekura Y, et al. Cochlear implant efficiency in pre- and postlingually deaf subjects. A study with $\mathrm{H} 2(15) \mathrm{O}$ and PET. Brain 1996;119(Pt 4):1297-1306

26 Carvalho B, Hamerschmidt R, Wiemes G. Intraoperative Neural Response Telemetry and Neural Recovery Function: a Comparative Study between Adults and Children. Int Arch Otorhinolaryngol 2015;19(01):10-15

27 Kutscher K, Goffi-Gomez MVS, Befi-Lopes DM, Tsuji RK, Bento RF. Implante coclear: correlação da recuperação neural, privação auditiva e etiologia. Pró-Fono R. Atual. Cient. 2010;22:473-478

28 Miller CA, Hu N, Zhang F, Robinson BK, Abbas PJ. Changes across time in the temporal responses of auditory nerve fibers stimulated by electric pulse trains. J Assoc Res Otolaryngol 2008;9(01): 122-137

29 Alvarez I, de la Torre A, Sainz M, Roldán C, Schoesser H, Spitzer P. Using evoked compound action potentials to assess activation of electrodes and predict C-levels in the Tempo+ cochlear implant speech processor. Ear Hear 2010;31(01):134-145 